\title{
Bolos artesanais: saberes populares fazendo-se saberes escolares
}

\author{
Handmade cakes: popular knowledge making school knowledge \\ Pasteles artesanos: el conocimiento popular se convierte en conocimiento \\ escolar
}

\author{
Lúcia Fernanda Renner, (renner723@gmail.com) \\ Universidade Regional Integrada do Alto Uruguai e das Missões - URI.
}

Luciana Dornelles Venquiaruto, (venquiaruto@uri.com.br)

Universidade Regional Integrada do Alto Uruguai e das Missões - URI.

Cênio Back Weyh, (ceniow@ san.uri.br)

Universidade Regional Integrada do Alto Uruguai e das Missões - URI.

Resumo: O presente trabalho foi desenvolvido com o intuito de dar visibilidade a saberes usualmente silenciados no currículo escolar. $\mathrm{O}$ artigo apresenta os resultados de uma pesquisa que investigou os saberes populares relacionados ao preparo artesanal de bolos com um grupo de boleiras da região missioneira do Rio Grande do Sul. O objetivo da pesquisa foi valorizar e estudar estes saberes populares com a intensão de torná-los saberes escolares, mais especificamente saberes que envolvam o ensino da Química. A pesquisa caracteriza-se como do tipo etnográfica. Foram utilizadas técnicas de entrevistas e da observação participante, com a finalidade de evidenciar os saberes da prática cotidiana sobre o preparo de bolos artesanais. A interlocução com as informantes da pesquisa possibilitou reflexões acerca desta investigação e estas, por sua vez, propiciaram a construção de interações a serem desenvolvidas no âmbito escolar, mais especificamente referente a conteúdos curriculares que envolvem reações químicas e funções inorgânicas.

Palavras-chave: Bolos artesanais; Saberes populares; Saberes escolares

Abstract: The present work was developed with the intention of giving visibility to knowledge usually silenced in the school curriculum. The article presents the results of a research that investigated popular knowledge related to the artisanal preparation of cakes with a group of cakes from the missionary region of Rio Grande do Sul. The objective of the research was to value and study this popular knowledge with the intention of making it school knowledge, more specifically knowledge that involves teaching chemistry. The research is being characterized as ethnographic. Identification techniques and participant observation were used, with the conditions to highlight the knowledge of daily practice on the preparation of handmade cakes. The interlocution with as informants of the research allowed reflections about this investigation and these, in turn, provided the construction of interactions to be developed in the school context, 
more specifically referring to curricula that involve active reactions and inorganic functions.

Keywords: Handmade cakes; Popular knowledge; School knowledge.

Resumen: El presente trabajo se desarrolló con la intención de dar visibilidad a conocimientos que suelen estar silenciados en el currículo escolar. El artículo presenta los resultados de una investigación que investigó el conocimiento popular relacionado con la elaboración artesanal de tortas con un grupo de tortas de la región misionera de Rio Grande do Sul. El objetivo de la investigación fue valorar y estudiar este conocimiento popular con la intención de convertirlo en conocimiento escolar, más específicamente en conocimientos relacionados con la enseñanza de la Química. La investigación se caracteriza por ser etnográfica. Se utilizaron técnicas de entrevista y observación participante con el fin de resaltar los conocimientos de la práctica diaria en la elaboración de pasteles artesanales. La interlocución con los informantes de la investigación permitió reflexiones sobre esta investigación y estas, a su vez, propiciaron la construcción de interacciones a desarrollar en el contexto escolar, más específicamente referido a conteidos curriculares que involucran reacciones químicas y funciones inorgánicas.

Palabras-clave: Pasteles Hechos a Mano; Conocimiento Popular; Conocimiento Escolar

\section{INTRODUÇÃO}

Uma parcela significativa da sociedade brasileira, ainda nos dias atuais, possui uma visão supervalorizada da ciência, entendendo o conhecimento científico como verdadeiro e, portanto, legítimo. Por vezes, esta visão cientificista é, também, reproduzida na escola.

Diante desse contexto, alguns pesquisadores em educação em ciências (como CHASSOT, 2006; GODIM; MOL, 2008; RESENDE; CASTRO; PINHEIRO, 2010; VENQUIARUTO; DALLAGO; DEL PINO, 2014; NONNEMACHER, 2018, RENNER et al., 2020) defendem que a escola deva valorizar não só o conhecimento científico, mas também o saber popular, o saber local, próprio da comunidade em que está inserido. Neste mesmo sentido muitos pesquisadores como (MOURA; SOUSA; CARNEIRO, 2018; ALVES; TOUTONGE, 2020; FERREIRA; MÜNCHEN, 2020) reforçam a importância de um ensino de ciências contextualizados. 
Assim, reforça-se a importância de dar visibilidade a saberes usualmente silenciados no currículo escolar, colocando-os em interlocução com saberes legitimados em nossa sociedade. Acredita-se, portanto, ser válido proporcionar aos alunos não só o conhecimento científico, por vezes transmitido de maneira descontextualizada, mas oportunizar, também, estudos relacionados a outras formas de produção de conhecimento, principalmente vinculados às suas raízes e a sua cultura.

Segundo Venquiaruto, Dallago e Del Pino (2014), há múltiplos saberes que estão associados a diferentes culturas e diferentes práticas sociais que fazem parte do nosso cotidiano, seja nas lutas diárias por sobrevivência, seja nas simples ações que compõem o nosso dia a dia. Neste sentido, Pomeroy (1994) considera importante que sejam desenvolvidos currículos de ciências em torno de conteúdos científicos que valorizem práticas e técnicas populares.

É imperativo destacar que, ao se propor investigar saberes populares de um determinado grupo social, não se tem a pretensão de apontar para uma uniformidade ideal de saberes, nem a pretensão de descrever "receitas" para outros tantos grupos que formam seus próprios processos de vivência e sobrevivência. O que se pretende é estudar saberes que constituem práticas políticas desses grupos específicos e valorizar suas diferentes maneiras de expressão. Nesta acepção, Lopes $(1999$, p.45) afirma que "é com a pluralidade de saberes que precisamos aprender a conviver".

Nessa perspectiva, efetuamos um estudo envolvendo a valorização de saberes populares relacionados com a produção artesanal de bolos, com um grupo de boleiras da região missioneira do Rio Grande do Sul, com o intuito de valorizá-los e estudá-los, e por intermédio de uma transposição didática, transformá-los em saberes escolares que contemplem o ensino de Química. Neste artigo, apresentam-se os resultados dessa pesquisa, com o intuito de compartilhar com o coletivo que faz educação por intermédio da Química.

\section{UMA FATIA DA HISTÓRIA}

Denomina-se bolo o produto assado, preparado à base de farinhas ou amidos, incluindo açúcar, fermento químico ou biológico, podendo conter leite, ovos, manteiga 
ou gordura vegetal e substâncias flavorizantes alimentícias, que os diferem em sabor e aroma (ANVISA, 1978).

Desde há muito tempo, o homem vem tendo preferência por produtos de padaria ou confeitaria, que são crescidos ou fermentados (VITTI; GARCIA; OLIVEIRA, 1988).

No Brasil, a cultura do bolo está atrelada aos colonizadores portugueses. Estes trouxeram para as terras tupiniquins a tradição boleira, servindo-se dos elementos locais, reunindo-se aos recursos trazidos da Europa, farinha de trigo, ovos, especiarias. Desde o primeiro século da colonização, a doçaria portuguesa estava aclimatada e pujante em todos os centros de povoamento. "Era dever das moças saber bater um bolo. Sobremesa para o futuro marido. Alegria dos filhos. Oferta aos vizinhos prestimosos" (CASCUDO, 2004, p.308. Esse conceito utilitário e sentimental constituiu, até bem pouco tempo, um critério genérico e inevitável na educação feminina brasileira.

No século XVI, obras relacionadas a receitas de bolos e doces proliferaram na França e Itália. Este tipo de livro era destinado às damas e às senhoritas, visto que a atividade doceira era nesta época praticada por mulheres. (FLANDRIN; MONTANARI, 1998).

A presença de um bolo indicava recepção, visita, nascimento, festividade, novidade social. Sempre houve intenção ornamental no acabamento boleiro. Enfeitava-o com arabesco de açúcar, flores de papel, flores naturais. Em relação ao formato dos bolos, os redondos são os mais antigos da história, uma vez que facilitava a divisão igualitária de fatias. (CASCUDO, 2004).

No Rio Grande do Sul, a contribuição dos imigrantes teve influência na predileção e preparo dos bolos. Na Região das Missões, os imigrantes poloneses, austríacos, alemães e italianos contribuíram significativamente com a tradição boleira. Os bolos eram preparados com recursos locais, frutas da estação eram incorporadas à massa, a saber: laranja, goiaba, banana, uva. Algumas leguminosas, tubérculos e cereais também eram usadas para o preparo de bolos doces, tais como: amendoim, cenoura, mandioca e milho.

Na mescla da população rio-grandense, os filhos da terra, os imigrantes europeus e os africanos deixaram importante contribuição para o desenvolvimento gastronômico. 
Salienta-se que os povos indígenas e africanos, estes últimos vieram na condição de escravo trabalhador, desconheciam as técnicas confeiteiras, no entanto, com o passar dos anos, houve uma sobreposição étnica que resultou em um mosaico de saberes e sabores característicos da região missioneira. (MARQUETTO, 2015).

Durante muitos séculos, a produção de bolos foi uma atividade artesanal. Em pleno século XXI, esta prática ainda está presente em muitas cidades de pequeno porte, em especial na Região das Missões. No entanto, o bolo vem adquirindo crescente importância no que se refere ao consumo e à comercialização no Brasil. O desenvolvimento tecnológico possibilitou mudanças nas indústrias, transformando a produção de pequena para grande escala. (MOSCATTO; PRUDENCIO-FERREIRA; HAULY, 2004).

A essência básica da cultura brasileira, durante os séculos de colonização, a mescla entre povos indígenas, europeus e escravos trazidos da África, se complementa a partir do século XIX, com a imigração dos europeus, árabes e asiáticos, adicionando novas características ao panorama cultural brasileiro. De maneira geral, todos esses povos contribuíram para a cultura brasileira em vários aspectos como: dança, música, religiosidade, literatura, culinária, idioma, etc.

\section{APORTES METODOLÓGICOS}

O desenvolvimento desta pesquisa ocorreu no noroeste do estado do Rio Grande do Sul, mais especificamente na Região das Missões. A realização da parte empírica ocorreu em três (3) cidades da região Missioneira, a saber: Santo Ângelo, Vitória das Missões e São Luiz Gonzaga. Participaram dessa pesquisa cinco (5) boleiras reconhecidas em suas comunidades pela arte de fazer bolos. O trabalho de campo levou, em média, dois dias para cada boleira entrevistada e ocorreu no segundo trimestre de 2019.

A pesquisa desenvolvida fundamenta-se na abordagem qualitativa. (BOGDAN; BIKLEN, 1994). A metodologia empregada no desenvolvimento da parte empírica foi denominada do tipo "etnográfica", conforme orientação metodológica de Marli de André (1995). Como procedimento de investigação de inspiração etnográfica, foi feito 
uso da observação participante, de entrevistas e do diário de campo. Já a interpretação dos dados coletados nesta pesquisa, referente aos saberes das boleiras da região missioneira, seguiu a orientação de Angrosino (2009).

Com base na revisão da literatura sobre a elaboração de bolos, realizou-se a identificação de temas na organização das categorias de análise. As categorias foram iniciadas a partir de temas preconcebidos. Assim, durante as análises das entrevistas, procurou-se dar atenção às falas das depoentes, limitando-se a quatro aspectos:

1) o significado da produção de bolos para o grupo pesquisado;

2) o processo fermentativo;

3) técnicas utilizadas para saber se o bolo está assado; e,

4) origem dos saberes na elaboração de bolos.

É preciso mencionar que antes mesmo de realizar a parte empírica, já fora feita uma opção: a pretensão de relacionar os saberes que envolvem a produção de bolos com o ensino de química.

Nesse sentido, procurou-se dar atenção, no decorrer da análise dos dados coletados, nas questões que, no entender dos pesquisadores, eram importantes para o desenvolvimento desta pesquisa, ou seja, plausíveis de relacionar com os conteúdos formais de química. Assim, fez-se uso da própria indução para selecionar o que se considerou como importante. Ressalta-se que outros pesquisadores poderiam ter outro olhar sobre a mesma temática.

\section{RESULTADOS E DISCUSSÕES}

Por intermédio das observações realizadas e pelas análises das entrevistas, percebeu-se que o significado da prática que envolve a elaboração de bolos é o mesmo para o grupo pesquisado. Em termos de significado da produção e das técnicas e procedimentos utilizados, as cinco boleiras entrevistadas responderam que preparar bolos vai além de promover um alimento rápido e saboroso para família, que é mais que contribuir com a renda familiar. A confecção de bolos tem um significado afetivo, conforme demonstrado nas falas a seguir: 
B1[...] fazer um bolo para a minha familia é como dar um abraço... é uma demonstração de carinho...receber amigos com um bolo fresquinho é como dizer que eles são especiais...presentear familiares, amigos ou vizinhos com bolos é um gesto de gratidão [...].

B4 [...] não tem como explicar, eu gosto muito... não é só fazer e vender, pois muitas vezes não te dá o lucro que espera, mas aquilo que tu sentes quando entrega o bolo e a pessoa elogia... isso é muito gratificante [...].

Ainda sobre o significado da confecção de bolos, as entrevistadas afirmaram que não consomem bolos industrializados, apenas os produzidos em suas residências, conforme destacam as falas a seguir:

B3 “[...] não compramos bolos prontos, todos os bolos consumidos nesta casa são feitos por mim! O bolo que eu faço é mais saboroso [...] acho que é porque é feito com amor, né?"

B5 “[...] compro bolo no dia da festa da padroeira [...] sabe como é [...] para ajudar a paróquia. Aqui em casa todos gostam dos meus bolos.'

Assim, observa-se que o ato de fazer bolo gera um bem-estar para quem o faz. Há uma valorização dos familiares e das pessoas próximas. Pode-se dizer que fazer bolos tem um significado maior que promover alimentos para a família, significa dedicação, significa uma demonstração de carinho para com as pessoas com quem se convive. Salienta-se que as receitas de bolos no grupo pesquisado são passadas de geração a geração e, muitas delas, estão registradas em cadernos de receitas confeccionados ainda pelas avós das entrevistadas.

Neste sentido, saberes que envolvem o preparo de bolos estão protegidos por registros em cadernos de receita, nos quais era costume identificar o nome da pessoa que havia passado a receita. (MARQUETTO, 2015).

No entanto, estes cadernos de receitas, comuns até a década de 80 do século passado, poderão cair no esquecimento. Observou-se nas entrevistas com as boleiras que há uma preocupação com a continuidade dos saberes em virtude das modernas tecnologias que, inquestionavelmente, são um facilitador da vida cotidiana. Segundo as boleiras: 
B1 "Quando as pessoas que herdaram estes cadernos de receitas passarem [...] temo que muitos conhecimentos passarão".

B4 "Peço para que não percam as receitas antigas e que estas não fiquem guardadas somente, pois hoje em dia está tudo muito industrializado [...] Faço alguns cursos onde temos as pré-misturas prontas onde as colegas mais novas não têm noção dos ingredientes que estão ali, só misturamos o leite e água [...] o mais importante é não perder o foco e não deixar as receitas antigas se perderem”.

B5 "Como eu faço bolos para a escola tanto os meninos quanto as meninas me pedem as receitas [...] teve um menino que pediu e eu comecei a falar e ele disse: - Ahh diz certinho para eu anotar [...] eles já estão com os papeizinhos para anotar [...] eles pedem para os pais fazerem e quando os pais não fazem eles mesmos fazem e me contam $[\ldots] ”$.

Enfatiza-se nestas falas a eminente preocupação de que os saberes que envolvem o preparo de bolos regionais caiam no esquecimento. Também se observa uma mudança de hábito cultural. Atualmente, meninos e meninas se interessam pela arte culinária das avós das entrevistadas.

\section{$4.1+\mathcal{O}$ PROCESSO FERMENTATIVO}

Fermento químico é o produto formado de substância ou mistura de substâncias químicas que, pela influência do calor e/ou umidade, produz desprendimento gasoso capaz de expandir massas elaboradas com farinhas, amidos ou féculas, aumentando-lhes o volume e a porosidade. (ANVISA, 1977).

Fermento em pó, outro nome atribuído ao fermento químico, geralmente contém três componentes principais: uma fonte de dióxido de carbono (bicarbonato de sódio $\mathrm{NaHCO}_{3}$ ), um ácido para reagir com o bicarbonato de sódio (fosfato monocálcio hidratado - $\left.\mathrm{Ca}\left(\mathrm{H}_{2} \mathrm{PO}_{4}\right)_{2}\right)$ e um agente enchedor que deve ser inerte. (VITTI;GARCIA; OLIVEIRA, 1988). Este último componente normalmente é o amido de milho $\left(\mathrm{C}_{6} \mathrm{H}_{12} \mathrm{O}_{6}\right)$ e serve para separar o bicarbonato de sódio, a fim de prevenir a ação prematura entre eles, liberando o gás carbônico durante o armazenamento. (MORETTO; FETT, 1998). O amido vai absorver a umidade do ar, mantendo o bicabornato de sódio 
e os elementos ácidos separados e secos, evitando que o bicarbonato de sódio reaja com o ácido contido na formulação.

Os fermentos químicos agem pela interação de um ou mais componentes ácidos com o bicarbonato de sódio. O crescimento da massa crua de bolo produzida pela ação do bicarbonato depende da reação entre um ácido fraco, HA, e os íons bicarbonatos, também conhecidos como hidrogenocarbonatos (ATKINS; JONES, 2006; RUSSELL, 2013), conforme demostra a Equação 1.

$$
\mathrm{HA}(\mathrm{aq})+\mathrm{HCO}_{3}-(\mathrm{aq}) \rightarrow \mathrm{A}-(\mathrm{aq})+\mathrm{CO}_{2}(\mathrm{~g})+\mathrm{H}_{2} \mathrm{O}(\mathrm{l})
$$

$\mathrm{O}$ bicarbonato reage com ácidos e formam o gás $\mathrm{CO}_{2}$. A reação de um bicarbonato $\left(\mathrm{HCO}_{3}\right)$ com um ácido produz primeiro o ácido carbônico $\left(\mathrm{H}_{2} \mathrm{CO}_{3}\right)$, o qual é instável e se decompõe em água $\left(\mathrm{H}_{2} \mathrm{O}\right)$ e $\mathrm{CO}_{2}$ (BROWN et al., 2012). A Equação 2 demostra esta decomposição:

$$
\mathrm{H}_{2} \mathrm{CO}_{3}(\mathrm{aq}) \rightarrow+\mathrm{H}_{2} \mathrm{O}(\mathrm{l})+\mathrm{CO}_{2}(\mathrm{~g})
$$

A finalidade do fermento químico na confecção de bolos é a levedação (do latim levere, significando elevar ou tornar leve), ou seja, fazer com que os produtos assados cresçam pela produção de minúsculas bolhas do gás dióxido de carbono $\left(\mathrm{CO}_{2}\right)$. As bolhas do $\mathrm{CO}_{2}$ são liberadas dentro da massa úmida, depois que o calor do forno as expande. Por este motivo, os bolos só devem ser colocados no forno quando este já estiver aquecido. (WOLKE, 2005). É isto que justifica, em parte, os saberes das boleiras participantes desta pesquisa, as quais são unânimes em afirmar que bolos só podem ser assados quando o forno estiver aquecido.

Essa mesma justificativa vale para o saber referente à temperatura ideal que os ingredientes devem ser misturados para se obter bolos fofinhos. Segundo as boleiras entrevistadas, não se pode adicionar leite ou água quente na massa do bolo caso deseje um bolo macio. A explicação para esta técnica é que, ao misturar ingredientes quentes, 
estes farão com que o fermento perca a eficácia, uma vez que o fermento iniciará a liberação de $\mathrm{CO}_{2}$ antes de ir ao forno, ou seja, antes da massa ter assado suficientemente para prender as bolhas de dióxido de carbono.

É com o aumento da temperatura que a maior ação do fermento vai se dar, ou seja, quanto mais quente a massa dentro do forno estiver, mais líquida ela se torna. No momento em que a massa atinge $60^{\circ} \mathrm{C}$, as proteínas do ovo coagulam, tornando-a mais firme. As bolhas de ar se estabilizam, a fermentação cessa e a massa passa a sofrer outras reações químicas, responsáveis pela coloração dourada, pelo sabor e aroma. (GALVÃO, 2017).

A estrutura de um bolo é criada através da combinação da farinha com as proteínas do ovo e do leite (quando usado), além de um forno aquecido. Sem essa estrutura bem formada, o fermento pode até agir na massa, mas o bolo poderá murchar ao ser retirado do forno. Bolos com excesso de farinha ou de ovos tornam a estrutura muito firme e assim o dióxido de carbono $\left(\mathrm{CO}_{2}\right)$ não consegue se expandir, deixando o bolo duro. (GALVÃO, 2017). Segundo as boleiras:

B1 "[...] o preparo de bolos deve seguir fielmente a receita porque o excesso ou a economia de um ingrediente poderá deixar o bolo abatumado. Se abrir o forno antes que a massa esteja firme, também, o bolo vai abatumar".

B2 “[...] é necessário seguir a receita certinha, bater bem as claras em neve, aquecer sempre o forno e não abrir ele antes de sentir o cheirinho".

B5 “[...] é necessário bater as claras em neve bem batidas, às vezes meu fermento está pouquinho aí coloco pouco e às vezes não coloco, cuidar também o açúcar e o óleo que deixa o bolo pesado".

Bolo sem a presença do fermento químico deixará o preparo pesado, com pouco volume e textura compactada. Quando o fermento químico não era acessível a toda população, as boleiras que participaram desta pesquisa relataram que suas mães e avós batiam as claras dos ovos separadas da mistura do bolo e só a misturavam pouco antes do bolo ir ao forno, deixando assim a massa mais aerada e fofa. Segundo Vitti, Garcia e Oliveira (1998), a ação da batedura dos ovos faz com que a massa fique espumosa, 
devido ao ar que é incorporado. Este ar expande-se assim que o produto vai ao forno, resultando num aumento de volume no produto final.

No entanto, essa utilização tinha os seus limitantes, pois os bolos eram batidos à mão, devido à tecnologia pouco desenvolvida na época. Somente a partir da década de 1930, o fermento químico da marca Royal® passou a ser fabricado e comercializado no Brasil e, aproximadamente 30 anos mais tarde, as indústrias Fleischmann® entram no mercado brasileiro com a produção de fermento químico. Atualmente, muitas marcas de fermento químico estão disponíveis para comercialização. É inegável que o fermento químico passou a ser um facilitador dos apreciadores da arte de fazer bolos.

\subsection{TÉCNICAS UTILIZADAS PARA SABER SE O BOLO ESTÁ ASSADO}

Em relação ao tempo de preparo do bolo no forno, as boleiras participantes da pesquisa foram unânimes em dizer que, para saber se o bolo está pronto, "é só aguardar o cheiro de bolo assado que invade a cozinha”. Outra informação que uma das depoentes repassou sobre o momento que o bolo está pronto é "visualizar a cor dourada do bolo". Enfatizou ainda "que somente neste momento o forno poderá ser aberto", referindo-se ao momento que se pode espetar um palito no bolo para ver se o mesmo sai limpinho, indicando assim que o bolo está assado.

Segundo Galvão (2017), quando o bolo libera um cheirinho inconfundível, é o momento que o forno poderá ser aberto e fazer o teste do palito, sempre espetando o palito no centro do bolo, já que o bolo assa das bordas para o meio. Deve-se ter cuidado para não se precipitar e furar a massa antes do bolo estar estruturado, pois o gás carbônico poderá ser liberado fazendo com que o bolo murche. A mesma autora enfatiza a importância de não abrir o forno antes que o bolo esteja estruturado, porque o ar frio que está no ambiente da cozinha vai gerar diferença de pressão dentro do forno, fazendo com que o bolo afunde.

\subsection{ORIGEM DOS SABERES NA ELABORAÇÃO DE BOLOS}


No decorrer das entrevistas realizadas, as boleiras afirmaram que seguem as receitas dos bolos na íntegra e que as receitas foram ensinadas pelas mães e avós, enfatizando a origem do saber disseminado. Como evidenciamos nas falas a seguir:

B2. “[...] eu aprendi com minha avó que era muita prendada... ela fazia bolos e doces... sempre com suas latas cheias... ela me ensinou a ver que o bolo está pronto pelo cheiro e com a faca".

B3 “[...] sempre segui a receita certinha, porque se eu mudar o que minha "nona” e minha mãe faziam pode não dar certo [...]"

B4 "[...] a minha irmã mais velha que me passou, faz muito tempo... minha mãe ensinou minha irmã...minha avó ensinou minha mãe".

B5 “[...] eu aprendi há muito tempo, ainda quando criança, minha avó materna era uma doceira de mão cheia, ensinou minha mãe e minha mãe me ensinou”.

Percebe-se a relevância do saber repassado de mãe para filha, pois as mães eram/são as detentoras dos saberes que envolviam/envolvem as técnicas dos confeitos, em especial nesta pesquisa as receitas de bolos, e com o objetivo de transmitir esta sabedoria, ensinavam as filhas. Portanto, esse saber familiar torna-se saber da comunidade, ensinado de geração para geração, ou seja, denomina-se educação popular, quando transferido entre grupos ou pessoas. (CEOLIN; CHASSOT; NOGARO, 2015).

Já Santos e Nagashima (2017, p.129) ressaltam que "a valorização dos saberes tradicionais e populares de um determinado grupo é muito importante, pois, além de resgatarem os saberes quase esquecidos no tempo, proporcionam também o fortalecimento e a difusão destes saberes para a sociedade".

No entanto, é notório que o preparo de bolos típicos da Região das Missões vem perdendo certas características histórico-culturais, uma vez que a memória coletiva e o saber oriundo do processo de elaboração destas preparações tradicionais estão desaparecendo, por conta da facilidade da aquisição de bolos industrializados e pela facilidade de acesso a bolos estranhos à cultura de origem.

\section{CONSIDERAÇÕES FINAIS}


Nesta investigação, procurou-se demostrar que é possível valorizar os saberes referentes à arte de fazer bolos, de uma determinada região do Brasil, com os saberes escolares, mais especificamente com os saberes que envolvem o ensino de química.

Sendo assim, entende-se possível redimensionar as relações do conhecimento escolar com as diferentes culturas, não desmerecendo os saberes oriundos de culturas populares por entendê-las como algo inferior, mas também não os isentando de questionamentos, assim como não cabe estabelecer a cultura dominante como padrão único a ser seguido ou simplesmente rejeitá-la.

Ressalta-se que a contextualização do ensino de química com os saberes referentes ao preparo de bolos apresentou-se como um excelente dispositivo pedagógico, o qual possibilita que alguns conteúdos programáticos do currículo escolar de química atuem como aglutinadores da diversidade de necessidades e de significados atribuídos pelos estudantes sobre os saberes populares estudados. Mais do que isso, possibilita que esses significados sejam reconstruídos. 


\section{REFERÊNCIAS}

ANDRÉ, Marli Eliza Dalmazo Afonso de. Etnografia da prática escolar. Campinas: Papirus, 1995.

ANGROSINO, Michael. Etnografia e observação participante. Porto Alegre: Artmed, 2009.

ANVISA. Agência nacional de vigilância sanitária. Resolução - CNNPA n. 38, de 1977. Aprova como coadjuvantes da tecnologia de fabricação as substâncias constantes dos anexos I, II, III e IV, destinadas ao fabrico de produtos forneados, tais como: pão, broa, biscoito, bolacha, bolo, torta e demais produtos afins de confeitaria. Diário Oficial [da] República Federativa do Brasil, Brasília, DF, 27 dez. 1977. Disponível em: http://portal.anvisa.gov.br/documents/33916/391619/RESOLUCAO_CNNPA_38_1977 .pdf/fedc31c9-811f-4f43-a90d-58f5f4d72bad. Acesso em: 04 abr. 2020.

Agência nacional de vigilância sanitária. Gerência Geral de Alimentos: Resolução - CNNPA $\mathrm{n}^{\mathrm{o}} 12$ de 1978. Disponível em: http://www.editoramagister.com/doc_308643_RESOLUCAO_No_12_DE_MARCO_D E_1978.aspx. Acesso em: 04 abr. 2020.

ATKINS, Peter; JONES, Loretta. Princípios de química: questionando a vida moderna e o meio ambiente. Porto Alegre: Bookman, 2006.

BOGDAN, Robert; BIRKLEN, Sári Knopp. Investigação qualitativa em educação: Uma introdução à teoria e aos métodos. Porto Editora: Portugal, 1994.

BROWN, Theodore L. et al. Química: a ciência central. São Paulo: Pearson Prentice Hall, 2012.

CASCUDO, Luís da Câmara. História da alimentação no Brasil. São Paulo: Global, 2004. 42.

CEOLIN, Izaura; CHASSOT, Attico Inácio; NOGARO, Arnaldo. Ampliando a alfabetização científica por meio do diálogo entre saberes acadêmicos, escolares e primeiros. Revista Fórum Identidades, v. 18, p. 13- 34, 2015.

CHASSOT, Atico Inácio. Alfabetização científica: questões e desafios para a educação. 4. ed., Ijuí: Ed. Unijuí, 2006.

DA SILVA ALVES, Eliene.; CAMPOS POJO TOUTONGE, Eliane. Os saberes das águas no ensino de ciências: intertrocas de conhecimentos e pessoas. Revista Insignare Scientia - RIS, v. 3, n. 4, p. 286-302, 20 nov. 2020. DOI: https://doi.org/10.36661/2595-4520.2020v3i4.11822

FERREIRA, Maiara Aparecida.; MÜNCHEN, Sinara. A contextualização no ensino de ciências: reflexões a partir da Educação do Campo. Revista Insignare Scientia - RIS, 
v. 3, n. 4, p. 380-399, 20 nov. 2020. DOI: https://doi.org/10.36661/2595$4520.2020 \mathrm{v} 3 \mathrm{i} 4.11825$

FLANDRIN, Jean Louis; MONTANARI, Massimo (Org.). História da alimentação. São Paulo: Estação Liberdade, 1998.

GALVÃO, Joice. A química dos bolos: receitas e segredos para dias mais doces. São Paulo: Companhia das letras, 2017.

GONDIM, Maria Stela da Costa; MOL, Gerson de Souza. Saberes populares e ensino de Ciências: possibilidades para um trabalho interdisciplinar. Química Nova na Escola, n. 30, p.3-9, 2008.

LOPES, Alice Ribeiro Casimiro. Conhecimento Escolar: ciência e cotidiano. Rio de Janeiro: UERJ, 1999.

MARQUETTO, Rut Friedrich. Gastronomia tradicional: regiões missões e Central do RS - Brasil. Santo Ângelo: [s.n.], 2015.

MORETTO, Eliane; FETT, Roseane. Tecnologia de óleos e gorduras vegetais na indústria de alimentos. São Paulo: Varela, 1998.

MOSCATTO, Janaína Andréa; PRUDÊNCIO-FERREIRA, Sandra; HAULY, Maria Cecília de Oliveira. Farinha de yacon e inulina como ingredientes na formulação de bolo de chocolate. Ciência e Tecnologia de Alimentos, v. 24, n. 4, p. 634-640, 2004.

NONNEMACHER, Fernando. Saberes populares fazendo-se saberes escolares: um estudo envolvendo a produção artesanal de vinagre de vinho tinto da região fronteira noroeste gaúcha. 2018. 75 f. Dissertação (Mestrado em Ensino Científico e Tecnológico) - Universidade Regional do Alto Uruguai - Campus Santo Ângelo, RS, 2018.

POMEROY, Deborah. Science education and cultural diversity: mapping the field. Studies in Science Education, n. 24, p. 49-73, 1994.

RENNER, Lúcia Fernanda et al. Bolos missioneiros: Química, cultura e memória. Cruz Alta, RS: Ilustração, 2020.

RESENDE, Daniela Regina; CASTRO, Ronaldo Antônio; PINHEIRO, Paulo César. O saber popular nas aulas de Química: relatos de experiência envolvendo a produção de vinho de laranja e a sua interpretação no ensino médio. Química Nova na Escola, n. 30, p. 3-9, 2010.

RUSSELL, John Blair. Química Geral. São Paulo: Makron books, 2013.

SANTOS, Diego Marlon; NAGASHIMA, Lucila Akiki. Saber popular e o conhecimento científico: relato de experiência envolvendo a fabricação de sabão caseiro. REnCiMa, v.8, n.2, p.127-142, 2017. 
TARGINO DE MOURA, Francisco Marconcio; SOUSA, Roselene Ferreira.; E SÁ CARNEIRO, Claudia Christina Bravo. O Ensino de Química contextualizado: as vozes discentes. Revista Insignare Scientia - RIS, v. 1, n. 3, 17 fev. 2019. DOI: https://doi.org/10.36661/2595-4520.2018v1i3.8849

VENQUIARUTO, luciana dornelles; DALLAGO, rogério marcos; DEL PINO, josé cláudio. Saberes populares fazendo-se saberes escolares: um estudo envolvendo pão, o vinho e a cachaça. Curitiba, PR: Appris, 2014.

VITTI, Policarpo; GARCIA, Eloísa Elena Corrêa; OLIVEIRA, Léa Mariza de. Tecnologia de biscoitos: manual técnico n. 1, Campinas: Ital, 1988.

WOLKE, Robert L. O que Einstein disse a seu cozinheiro: mais ciência na cozinha. Rio de Janeiro: J. Zahar, 2005.

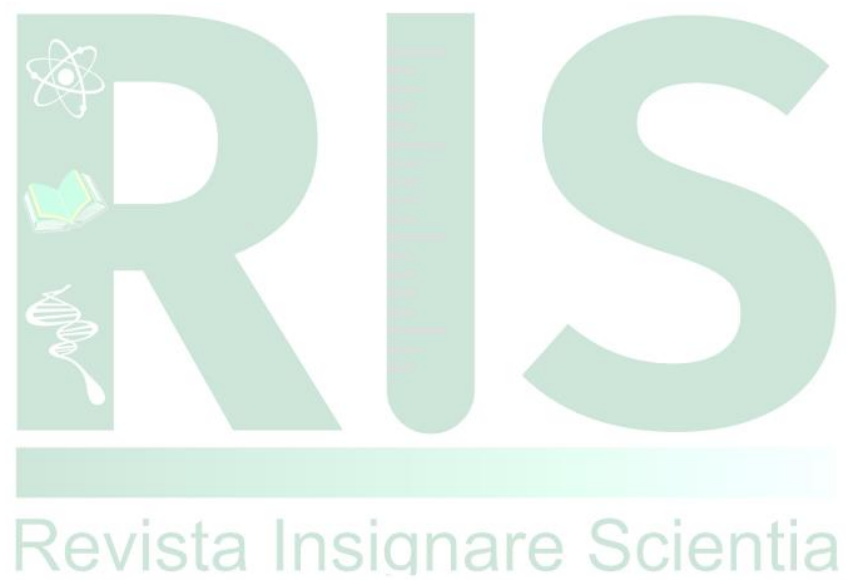

